\title{
Organization of distance education in chemistry in higher education
}

\author{
V.V. Shakirova ${ }^{1 *}, O . S$. Sadomceva ${ }^{2}$, and L.A. Dzhigola ${ }^{3}$ \\ ${ }^{1}$ Astrakhan State University, Astrakhan, Russia \\ ${ }^{2}$ Astrakhan State University, Astrakhan, Russia \\ ${ }^{3}$ Astrakhan State University, Astrakhan, Russia
}

\begin{abstract}
The study focuses on the problems of distance learning in higher natural science education (using the example of chemical education). The issues of history of development of means and methods of e-learning using remote educational technologies are discussed. The study focuses on the activities of the Department of Analytical and Physical Chemistry of Astrakhan State University in the field of organizing and conducting classes in specialized chemical disciplines with students during the period of self-isolation. Attention is paid to the organization and conduct of distance learning during the period of self-isolation, through the Moodle virtual educational environment. Advantages and disadvantages of distance learning, difficulties of conducting classes in a distance form in the discipline of "chemistry," as well as factors ensuring obtaining quality education are considered.
\end{abstract}

\section{A problem statement}

The current circumstances in the context of the coronavirus pandemic have negatively affected the national education systems of all countries. In fact, the education system around the world was challenged. According to the Order of the Ministry of Education and Science of the Russian Federation N. 398, in order to protect the health of all students, teachers and employees of educational organizations, Russian educational institutions have switched to electronic and distance learning. The teachers were given an extremely difficult task - to ensure the implementation of educational programs in full.

In extreme conditions of transition to distance learning, most teachers did not have enough knowledge and skills in the field of computer literacy, there was no time to master new tools. It was also not possible to train teachers in a pandemic. Questions of detailed development of courses and pedagogical design of disciplines were not even raised. All universities were forced to combine all their resources and urgently, massively introduce elearning using remote educational technologies [1].

Depending on the level of development of IT infrastructure, access to various services and platforms, each university has formed its own scenario for implementing training in an online environment. The choice of most universities focused on the use of LMS (Learning

*Corresponding author: prof-ped.gpa@mail.ru 
Management System) - platforms for e-learning, in combination with webinar services for online lectures and consultations, social networks, etc. [2, 3].

\subsection{The objective of the work}

It is worth paying attention to the difference between the concepts of "e-learning" and "distance learning". According to the Federal Law "On Education of the Russian Federation", " e-learning - is the organization of educational activities using information technologies. Distance learning technologies are educational technologies that are implemented using information and telecommunications networks, at a distance, the interaction of students and teachers ".

\section{Materials and the results of the research}

The history of development, means, methods, technologies, and didactic foundations of distance learning are quite fully presented in the studies of E.S. Polat [4], Andreeva A.A., Traeynev V.A. [5], and others. Turning to the development of distance education abroad, we note that mass open online courses began to be actively developed in 2012, but since 2015, European and American universities have had to recognize the quality of online education as rather weak [6-9] and have reduced their importance among pedagogical approaches.

In Russia, today, distance education is spoken about at almost all levels, and the advantages and disadvantages are widely discussed. One of the main disadvantages of such education is the limited list of disciplines suitable for distance learning. One of these subjects is undoubtedly "Chemistry", where excessive "virtualization" can eventually lead to simplification and deterioration of the presentation of the material, so for a deeper understanding of the subject, the teacher's participation cannot be minimized. The use of elearning with the use of distance learning technologies in chemical education is allowed only for easy-to-learn subjects of the discipline and only in combination with classical education [10].

The complexity of e-learning using remote educational technologies is primarily due to the impossibility of conducting laboratory and practical work in the traditional format, which is an integral part of the discipline and does not allow to implement the practical competencies of the educational program.

In remote learning conditions, the experiment is replaced with demonstration videos and a theoretical discussion of the technique of its implementation. This cannot be compared with face-toface classes, where in the process of performing an experiment hands, students, along with knowledge, acquire real experimental skills and skills [2]. We emphasize that a feature of the chemical experiment in the higher school system is the mandatory availability of specialized equipment and reagents. Unlike the simplest experiments of the school course, laboratory work in specialized chemical disciplines, provided for in the curricula, cannot be carried out at home [10].

In the framework of this work, I would like to give an example of the organization of distance learning during the period of self-isolation, by teachers of the Department of Analytical and Physical Chemistry of Astrakhan University [11, 12]. For many years, the AGU website has been using an educational portal based on the Moodle system. This system has a large number of modifications in dozens of languages and is widespread throughout the world. At the Department of Analytical and Physical Chemistry, students have been learning topics for several years for independent study (as an addition to classroom classes) in specialized disciplines based on the Moodle system. In the pandemic 
environment, all classes were completely moved to the Moodle professional environment, combined with video conferencing lectures based on the Zoom platform.

Let's briefly talk about the reasons for choosing a system. The professional Moodle environment is easy to use. Tasks have time constraints, which allow the teacher to set the pace of the material and simultaneously control the time frame of its execution. The plus is the length of time the job file is stored. The system includes a wide range of material (glossary, tasks, lectures, the ability to insert videos, etc.), which can be used using tags and hyperlinks $[13,14]$.

Despite the fact that the Moodle system is focused on students' self-study of disciplines, it provides for feedback, student-teacher interaction (forum, blog, conferences, ads). A great advantage is the opportunity for the teacher to make changes as students master the course, as well as monitor the entire educational process, tracking attendance and time of completion of tasks [15].

The faculty of the department developed and placed in the Moodle system a complete package of materials for the most effective assimilation and more convenient use when students work independently. First of all, these are organizational documents and instructions for working with courses, including work programs, time schedules, schedule of classes, evaluation criteria (developed taking into account distance learning).

Lecture materials, both in text format and using copyright multimedia presentations, were posted on the portal. Note that the "distance" was carried out according to the schedule of classroom training. Each lecture occupation was organized in a videoconference format (a link to the saved video recording of the lecture was posted separately). The most difficult topics, for example, in the courses "Physical Chemistry" and "Colloidal Chemistry", were dealt with in more detail with comments and examples in the" question-answer " format, as well as using simulators of standard exercises and tasks.

To solve the problems with the absorption of the material from the laboratory and practical lessons, detailed instructions and methodological guidelines were developed, demonstration videos were selected on the topics of the laboratory workshop. To consolidate knowledge on each topic of laboratory and practical lessons, individual tasks for them were laid out. In the form of videoconferences for practical lessons, examples of solving problems that cause students the most difficulties were examined, which was combined with self-study of solving problems that are effective enough to obtain practical skills.

Separately, we will stop at organizing laboratory classes in a remote format. As noted above, the specifics and peculiarities of chemical education in higher education dictate certain requirements for the implementation of experimental work [16, 17]. Demonstration videos were selected for simpler works, for example, for laboratory classes to determine the heat of dissolution, neutralization, dissociation by calorimetry according to Physical Chemistry, for an experiment to obtain colloidal systems using various methods according to Colloidal Chemistry. According to more time-consuming experiments, analysis and discussion of the method of performing the experiment, the conditions for its implementation and mathematical processing of conditionally obtained results were carried out. Students prepared their own laboratory report, which made it possible to acquire skills in statistical processing of results. Questions and tasks for laboratory work were drawn up in such a way as to maximize all the features of the chemical experiment and consolidate the theoretical material. Note that students showed more interest in laboratory work and most actively participated in the discussion, compared to lecture classes.

As part of the consultations, in order to discuss incomprehensible issues and emerging issues, as well as to direct and adjust the self-activities of students in addition to video consultations, teachers actively used elements of the Moodle platform, such as a forum and 
interactive chat. This allowed students to ask questions not only during direct classes, but also at the time of completing tasks and preparing for classes [18].

For intermediate control in the Moodle educational environment, electronic testing is provided, which allowed teachers to monitor the level of assimilation of knowledge. To prepare for knowledge control, various reference materials were posted; links to e-learning publications, libraries and thematic sites).

In disciplines, the mastery of which ends with the exam, examination tests were carried out on the basis of the Zoom platform, in the format of video conferencing. The basis was the traditional certification system: ticket selection, preparation and oral response. The photo of the written response was sent by the student to the teacher's mail. It should be noted that the results of distance learning exams, in general, in all specialized disciplines of the department, showed a lower level of achievement compared to classical classroom learning $[19,20]$.

One of the problems of remote training is the difficulty of controlling the independence of the task. Often, some students use modern information technology to write off and reduce the load, and not to self-monitor the correctness of the task. When checking student assignments, the teacher needs more time, including in order to identify such students. That is why tasks and guidelines for their implementation should be developed taking into account this fact, which takes much longer.

When considering distance learning, questions about the motivation of students and their interest cannot be ignored. These conditions are mandatory for the effective development of theoretical foundations and the formation of practical skills of the student. A separate role should be given to self-discipline, self-knowledge and self-education. However, most modern students do not know how to work independently and are not ready for such an activity, despite the fact that the skill to work with various types of literary sources should be formed in high school. The lack of self-learning skills, self-knowledge and self-education limits the ability of students to achieve goals in distance learning [21].

Today, students are armed with numerous digital means that allow them access to a huge amount of information and provide a large number of opportunities to achieve their goals. In this regard, one of the main tasks of the teacher is to maintain the interest and desire of students to learn and receive new knowledge, skills and skills, in the form that is most attractive to them [22]. The teacher must monitor and direct the student's activities, so that gadgets and digital means remain only a means of learning, while maintaining the main goal - to prepare a specialist who is able to independently solve his tasks in the professional field. That is why the independent work of the student himself is the most important condition for the quality of the received education and the effectiveness of study. The main role in the learning process should be played by the student himself.

\section{Conclusions}

Thus, summing up the above, we note that learning in an electronic environment does not fully allow you to form the skills necessary to communicate with students. The damage is caused by the development of oral speech, the ability to competently use chemical terminology, explain the material, using various means of training, the formation of skills in group and pair interaction, etc. All this in the end can negatively affect the formation of competencies, the development of which is aimed at the development of this educational discipline.

However, the main advantage of distance education is considered the opportunity to receive the necessary knowledge at any university not only in Russia, but also in the world, with minimal financial costs for training. In our opinion, distance learning will be effective if the following conditions are met: the absolute readiness of both parties involved in the 
educational process. On the one hand, this is a student who is able to work independently and has the skills of self-knowledge and self-education. On the other hand, it is a complete set of methodological recommendations and materials, developed taking into account the specifics of the discipline and fully meeting the requirements of the curricula. Also, do not forget about the technical side of the educational process, jobs for both the student and the teacher should be technically equipped, the Internet access channel should have sufficient bandwidth.

Given all the above, in our opinion, distance learning can be an excellent aid to classical education in the field of natural science education, in particular chemical education.

\section{References}

1. M.W. Marek, C.S. Chew, Teacher Experiences in Converting Classes to Distance Learning in the COVID-19 Pandemic, International Journal of Distance Education Technologies, 19(1), 89-109 (2021)

2. E.N. Dronova, Organizational and pedagogical conditions for the effective use of the Moodle distance learning system in the academic process of master's studies at a pedagogical, Computer science and education, 7, 51-57 (2017)

3. A.B. Bakasheva, L.S. Hamidov Formations of students' readiness for self-education using distance technologies, MNO, 6(79), 323-325 (2019)

4. E.S. Polat Organization of distance education in the Russian Federation, Computer science and education, 4, 25-33 (2005)

5. V.I. Soldatkin, Informatics in the system of distance education at the turn of the XXI century, Distance education, 1, 9 (1998)

6. J. Sumner, Serving the System: A Critical History of Distance Education, Towson University, 4(1) (2003)

7. A. Margaryan, M. Bianco, Littlejohn, Instructional Quality of Massive Open Online Courses (MOOCs), Computers and Education, 80, 77-83 (2015)

8. M. Huchek, Innovation in enterprises and their implementation, 45-46 (1992)

9. D.V. Chernilevsky, O.K. Filatov, Innovative approaches to the organization of training, Specialist, 2(4), 50 (1997)

10. A.D. Ivanova, O.V. Murugova Online education through the eyes of students and teachers (following the results of the 2019 pedagogical study), Open education, 24(2), 4-16 (2020)

11. O.S. Sadomceva, L.A. Dzhigola, V.V. Shakirova, Propedevtika chemical knowledge of primary and primary school, Physics in school, S2, 186-189 (2020)

12. L.I. Zharkikh, N.M. Alykov, N.V. Zolotareva, Quantum ecological chemistry - new educational discipline for universities, Natural sciences, 4, 130-136 (2008)

13. M. Mukumov, Using the Moodle Distance Learning System in the Educational Process, Journal NX, 6(11), 156-159 (2020)

14. E. Shchedrina, I. Valiev, F. Sabirova, D. Babaskin, Providing Adaptivity in Moodle LMS Courses, International Journal of Emerging Technologies in Learning, 16(2), 95 107 (2021)

15. O.V. Zinina, J.A. Olentsova, University's problems in the era of distance learning technologies and their solution, Baltic Humanitarian Journal, 1(30), 57-59 (2020)

16. S.L. Bretz, Evidence for the Importance of Laboratory Courses, J. Chem. Educ, 96, 193-195 (2019) 
17. K. Pyatt, R. Sims, Virtual and Physical Experimentation in Inquiry-Based Science Labs: Attitudes, Performance and Access, J. Sci. Educ. Technol., 21, 133-147 (2012)

18. E.A. Alekhine, N.A. Makarova, Features of the organization of distance learning of organic chemistry in a pedagogical university in the conditions of the pandemic of coronavirus infection, Open education, 24(5), 36-45 (2020)

19. Z. Qiang, A. G. Obando, Y. Chen, C. Ye, Revisiting Distance Learning Resources for Undergraduate Research and Lab Activities during COVID-19 Pandemic, J. Chem. Educ., 97, 3446-3449 (2020)

20. A. Saar, M. Mclaughlin, R. Barlow, J. Goetz, A.W. Adediran, A. Gupta, Incorporating Literature into an Organic Chemistry Laboratory Class: Translating Lab Activities Online and Encouraging the Development of Writing and Presentation Skills, J. Chem. Educ, 97, 3223-3229 (2020)

21. S.S. Johnson, M.K. Gaines, M.J. Van Vleet, K.M. Jackson, C. Barrett, Unleashing Our Chemistry Superpowers: Promoting Student Success and Well-Being at a Black Women's College during COVID-19, J. Chem. Educ., 97, 3369-3373 (2020)

22. James R. Brinson, Learning outcome achievement in non-traditional (virtual and remote) versus traditional (hands-on) laboratories: A review of the empirical research, Computers \& Education, 87, 218-237 (2015) 